\title{
La «cuestión femenina» en el primitivo cristianismo hispano: a propósito de los cánones V, XXXV y LXXXI del Concilio de Elvira
}

\begin{abstract}
Aunque en varias ocasiones se ha recurrido al término «emancipación» para referirse a las transformaciones legales y socioeconómicas que afectan al status y forma de vida de la mujer romana de fines de la República e inicio del Imperio ${ }^{1}$, es evidente que no hay que buscar similitudes entre este proceso y otros vividos por la mujer en etapas históricas recientes, que responden a una clave histórico-cultural y una mentalidad muy diferente ${ }^{2}$. En Hispania, y en global en el mundo romano, las mayores beneficiarias de este proceso fueron las damas de
\end{abstract}

1 Cf. A. del Castillo, La emancipación de la mujer romana en el siglo i d. de C., Granada 1976; G. Fau, L'emancipation fémenine dans le Rome Antique, París, 1978; A. Sirago, Feminismo a Roma del Primo Imperio (s. l), 1983; Sobre la evolución de la situación femenina en Roma, cf. además C. Hermann, Le role judiciaire et politique des femmes sous la Republique Romaine. Bruxelas 1964; Histoire Mondiale de la Femme: Préhistoire et Antiquité, vol. I, bajo la dirección de P. Grimal, París 1974; S. B. Pomeroy, Goddesses, Whores, Wives and Slaves. Women in Classical Antiquity, New York 1975; E. Cantarella, L'ambiguo malanno. Condizione e immagine della donna nell' antichità greca e romana, Roma 1985; VV. AA., La mujer en el Mundo Antiguo. Actas de las V Jornadas de Investigación Interdisciplinaria, Madrid 1986; VV. AA., Historia de las mujeres en Occidente. I. La Antigüedad, Madrid 1991; M. H. Gallego Franco, Femina Dignissima. Mujer y Sociedad en Hispania Antigua, Valladolid 1991.

2 Cf. M. Perrot, Une histoire des femmes. Est-elle possible?, París 1984; L. J. Nicholson, Gender and History, New York 1986; C. Martínez López, «Reflexiones sobre la Historia de la mujer en el Mundo Antiguo», I Coloquio de Historia Antigua Peninsular, Santiago de Compostela 1988, 205-217. 
los grupos sociales privilegiados, cuya situación social y económica les situó en una posición favorable para sacar el máximo partido de las medidas legales que indirectamente liberalizaban su situación. Sin embargo, seguramente la evolución del status entre las mujeres de la aristocracia tendría sobre las más modestas un efecto de espejo que relajaría las costumbres y concepciones tradicionales.

Ahora bien, la nueva condición alcanzada por la mujer del Imperio nunca obtuvo un reconocimiento oficial. Las reformas legislativas y económicas que abrieron la puerta a la liberalización del status femenino no pretendían esa meta, y sin duda el resultado pilló de sorpresa a los propios varones romanos ${ }^{3}$. La literatura romana altoimperial, evidentemente masculina, nunca abandonó los tópicos tradicionales de la mujer virtuosa: castitas, puditicia, univira, lanifica o tejedora ${ }^{4}$, en definitiva, la domina o señora de la casa, la matrona influyente respetada por su marido, sus hijos y la servidumbre ${ }^{5}$. En el Derecho romano el status matronal, cuyo símbolo era la vestimenta, la estola y la cabeza cubierta ${ }^{6}$, era honrado y protegido ${ }^{7}$.

Esta dicotomía entre la situación de iure y la de facto de la mujer en el Imperio Romano, junto con la progresiva difusión del cristianismo y con la crisis de los valores del paganismo romano (mitad III-IV d. de C.), provocarán lenta, pero inexorablemente, un retroceso real en el status y capacidad de iniciativa de las mujeres romanas, y por extensión, hispanorro-

3 Plutarco, Cato Maior, 8, 4; Tito Livio, XXXIV, 3; Juvenal, Sat., VI; Catulo, Carm., LXX; Tácito, Dialogus de Oratoribus, 28.

4 Suetonio, Augustus, 64,2, donde se manifiesta que el trabajo de la lana era una actividad que honraba a la mujer de la casa, y así Augusto abligaba a sus hijas y nietas a tejer y a hilar, y usaba a diario la ropa tejida por las mujeres de su familia.

5 A. Pociña, «Mulier est: errat. Literatura masculina y mujer en el Imperio Romano. Propuestas metodológicas», en VV. AA, La mujer en el mundo mediterráneo antiguo. Granada 1990, 193-218.

6 L. Sensi, «Omatus e status sociale delle donne romane», Annali Fac. Lettere e Filosofia, 18,1, Universidad de Peruggia, 1980, 55-90.

7 Suetonio, Vita Augusti, 43; Seneca Orator, Controversiae, 2,7; Digesto, $43,30,3,6 ; 47,10,15,15 ; 50,16,46,1 ; \mathrm{M}$. Morabito, Les réalités de l'esclavage d'aprés le Dieste, Annales Littéraires de l'Université de Besançon, 254 (Centre de recherches d'Histoires anciennes, 39), París 1981, 190; Y. Thomas, «La división de los sexos en el Derecho Romano», en G. Duby - M. Perrot, Historia de las Mujeres en Occidente. La Antigüedad. Vol. I, Madrid, 1991, 151. 
manas. El ideal de mujer cristiana, influido por una fuerte herencia judaica y oriental, exigía a la mujer romana imperial una vuelta hacia el hogar y el poder masculino, al que se suma ahora el del sacerdote. Ello se realiza en un proceso gradual en el que abundan los puntos de contacto con los valores romanos tradicionales y su concepción conservadora de la figura femenina ${ }^{8}$, remachado por la legislación civil de los emperadores cristianos, que unida al derecho canónico refuerza el desplazamiento de la mujer en cuestiones claves: matrimonio, adulterio, divorcio $y$, en general, en la capacidad de ésta para tomar iniciativas propias 9 .

Ahora bien, esta involución de las posiciones femeninas no dejó de ser problemática. Desde sus primeros tiempos el cristianismo tuvo un éxito notable entre grupos de mujeres, algunas de las élites aristocráticas ${ }^{10}$. Estas primitivas cristianas

8 Pablo, I Cor, 11,10; A. Rousselle, «La política de los cuerpos: entre procreación y continencia en Roma», en G. Duby - M. Perrot, Historia de las Mujeres en Occidente. La Antigüedad. Vol. I. Madrid 1991, 340: buen ejemplo de esa identificación de la primitiva Iglesia cristiana con figuras y situaciones legales y morales del paganismo tradicional es la adopción del velo, uno de los distintivos de la matrona, por parte de las mujeres cristianas, to que las hace tener el aspecto de mujeres honorables, intocables, como lo era la dignitas de la matrona en el Derecho romano; J. M. Torres, «Optima Uxor/Impudica et perversa mulier en la epistolografía griega cristiana (ss. IV-v)», Faventia, 17/2, 1995, 62-65, insiste en la virtus entendida como castitas y puditicia como adomo de la esposa cristiana, en la línea de los valores tradicionales romanos. Cf. Clemente de Alejandría, lib. I, cap. IV, 10, 1; E. Conde, «La mujer ideal en el Pedagogo de Clemente Alejandrino», La Mujer en el Mundo Antiguo. Actas de las V Jornadas..., 329-342.

9 Codex Theodosianus, IX, 40, 1; IX, 1; IV, 6, 3; S. Jerónimo, Epistulae, 22,16; 22,$29 ; 38,3 ; 54,10 ; 107,10 ;$ M. D. Saavedra, «La mujer como inductora de un fenómeno económico, la inflacción, según Tertuliano", La Mujer en el Mundo Antiguo. Actas de las V Jornadas... 307-314; M. Marcos, «La visión de la mujer en San Jerónimo a través de su correspondencia», ibidem, 315-322; J. M. Torres, «Discriminación de la mujer en las relaciones matrimoniales según San Basilio de Cesarea», ibidem, 323-328; J. M. Torres, «Optima Uxor/Impudica et perversa mulier en la epistografia griega cristiana (ss. IV-v)», Faventia, 17/2, 1995, 60-61, señala la presentación de argumentos del Nuevo Testamento para esta discriminación, sobre todo las epístolas de Pablo (Timoteo 2, 13-14; Tito 2,5; Efesios 5, 22-25), así como la influencia de autores clásicos, como Platón, cf. E. A. Clark, «The virginal politeia and Plato's Republic: John Chrysostom on women and the sexual relation», Jerome, Chrysostom and Friends. Studies in Women and Religion, II, New York, 1979, 1-34.

10 Sobre el papel activo desempeñado por las mujeres en los principios del cristianismo: cf. A. Chastagnol, «Le sénateur Volusien et la conversion d'une famille de l'aristocratie romaine au Bas-Empire», REA 58, 1956, 241-153; P. R. L. Brown, «Aspects of the christianization of the roman aristocracy», JRS, 51, 1961, 1-11; 
demostraron ser uno de los sectores más dinámicos de la Iglesia, como evidencia su participación, junto a varones notables, en movimientos ascéticos y fundacionales "'. Excelentes exponentes de ello encontramos en damas hispanorromanas, como Cerasia $^{12}$, Terasia $^{13}$, Melania la Vieja ${ }^{14}$, Melania la Joven ${ }^{15}$ o Egeria ${ }^{16}$. Este dinamismo influyó sin duda en la temprana preocupación de los Padres de la Iglesia por la mujer, por enmarcar su educación y dirigir sus costumbres, sobre las que gravitaba el tópico de la inferioridad moral y espiritual femenina ${ }^{17}$. Finalmente, aunque el cristianismo primitivo suavizó su rigor en otros aspectos, no fue así en la cuestión femenina, que concluyó con la represión de la mujer en la comunidad familiar, social y religiosa, ámbitos en los que se restringe en gran medida su participación ${ }^{18}$.

Los aspectos relativos al matrimonio, adulterio y comportamiento sexual, son claves en relación a la figura femenina ${ }^{19}$, y centralizan el protagonismo de los cánones de los Concilia

\begin{abstract}
A. Yarbrough, «Christianization in the Fourth Century: the example of roman women", Church History, 45, 1976, 149-165; J. Laporte, The role of women in the early Christianity, New York 1982; R. MacMullen, La diffusione del cristianesimo nell'Impero Romano, Roma-Bari 1989, 44-47; M. Serrato, Ascetismo femenino en Roma, Cádiz 1993.
\end{abstract}

11 San Jerónimo, Epistulae, 66,13; H. Gallego, Femina Dignissima..., 130-155; cf. M. Serrato, Ascetismo femenino en Roma, Cádiz 1993.

12 Eutropio, De simul carn. pecc., PL., suppl., 1, col. 555.

13 J. M. Blázquez, «Problemas económicos y sociales en la vida de Melania la Joven y en la Hispania Lausiaca de Palladio», MHA, II, 1978, 104; P. Palol, «Romanos en la Meseta. El Bajo Imperio y la aristocracia indígena", Segovia. Symposium de arqueología romana, Publicaciones eventuales de la Universidad de Barcelona, XXVII, 1977, 307-308.

14 Palladio, Hispania Lausiaca, XLVI, 2; LIV, 4-5.

15 Geroncio, Vita S. Melaniae, X, 12; XIX, XXII, XLI, XLIX, LVII.

16 Valerio, Ep. Beat. Aeth., 1; Itin. Aeth., III, 8; V, 8; VII, 3; XII, 7; XIX, 19; XX, 13; XXIII, 10; XXIV, 1; XXVII, 2; XLVI, 1; XLVI, 4.

17 San Jerónimo, Epistulae, 79,8 .

18 Tertuliano, De virginibus velandis, 9,1; cf. E. Giannarelli, La tipologia femminile nella biografia e nell' autobiografia cristiana del N secolo, Roma 1980; J. Laporte, The role of Women in Early Christianity, Nueva York 1982; I. Rodriguez Herrera, Antigüedad Clásica y Cristianismo, Salamanca 1983; R. Teja, El cristianismo primitivo en la sociedad romana, Madrid 1990.

19 M. Ibarra, Mulier Fortis. La mujer en las fuentes cristianas, Zaragoza 1990, 248-249, incide en la amplitud de la temática femenina que recoge el Concilio de Elvira, atribuyéndola a la importacia del elemento femenino en la tarea evangelizadora, especialmente en la familia. 
hispanorromanos ${ }^{20}$ del siglo Iv, el de Elvira ${ }^{21}$, el de Zaragoza I y el de Toledo I. Sin embargo, en este caso han llamado nuestra atención los cánones $\mathrm{V}$ y XXXV del Concilio de Elvira, que se ubican en principio al margen de esta línea temática preponderante, pero cuyo análisis ofrece sin duda gran interés desde el punto de vista de la posición femenina en la Hispania del siglo iv.

El canon $\mathrm{V}^{22}$ fija las penas para las dominae responsables de haber causado la muerte a una ancilla o esclava doméstica. No representa una novedad la presencia de la violencia en las relaciones de dependencia ${ }^{23}$, y el tratamiento de la falta se ade-

20 J. Vives, Concilios visigóticos e hispano-romanos, Barcelona-Madrid 1963; G. Martínez - F. Rodríguez, La colección canónica hispana. IV. Concilios galos. Concilios hispanos: primera parte, Madrid 1984.

21 La situación en la que queda la mujer en estos temas en los concilios hispanorromanos ha sido ya objeto de exhaustivos e interesantes estudios, cf. P. Lombardia, "Los matrimonios mixtos en el Concilio de Elvira", A.H.D.E., 24, 1954, 543558; J. Gaudemet, «Elvire», Dictionnaire d'Histoire et de Géographie Ecclésiastique, 15, 1963, 317-348; E. Griffe, «A propos du canon 33 du concile d'Elvire», Bulletin de Littérature Ecclesiastique, 74, 1973, 142-143; E. Griffe, «Le concile d'Elvire et les origines du célibat ecclesiastique», Bulletin de Littérature Ecclésiastique, 77 , 1976, 123-127; M. Meigne, "Concile ou collection d'Elvire?", Revue d'Histoire Ecclésiastique, 70, 1975, 361-387; M. Sotomayor, Historia de la Iglesia. I. La Iglesia en la España Romana y Visigoda (Dir. R. García Villoslada), Madrid 1979, 81119; D. Ramos-Lisson, «Communio y recepción de cánones conciliares de los sínodos hispánicos en los siglos iv y v", Annuarium Historiae Conciliorum, 12, 1980, 26-37; D. Ramos-Lisson - J. Orlandis, Historia de los Concilios de la España romana y visigoda. Pamplona 1986; D. Ramos-Lisson, «En torno al papel de la mujer según el Concilio de Ilíberis», en W. Brandmüller - H. Immenkötter - E. Iserloh, Ecclesia militans. Studien zur Konzilien und Reformationonsgeschichte, I, Paderborn 1988, 83-95; J. Suberbiola, Nuevos concilios hispanorromanos de los siglos 111 y $\mathrm{W}$. La colección de Elvira, Málaga 1987; A. del Castillo, «Los impedimentos para el matrimonio con paganos en el Concilio de Elvira», Hispania, 151, 1982, 338-339; F. Paredes Fernández, «La problemática sexual en los Padres de la Iglesia. San Cipriano y el Concilio de Elvira", In Memoriam Agustín Diaz Toledo, Granada-Almería 1985, 294-295; M. Ibarra, "Las viudas en el Concilio de Elvira», Actas del II Congreso Peninsular de Historia Antigua, Coimbra 1993, 1079-1987; M. Ibarra, Mulier Fortis. La mujer en las fuentes cristianas, Zaragoza 1990, 199-247.

22 Si qua femina furore zeli accensa flagris uerberauerit ancillam suam eo quod incertum sit uoluntate au casu occiderit, si uoluntate, post septem annos; si casu, post quinquennii tempora acta legitima paenitentia ad communionem placuit admitti. Quod si infra tempora constituta fuerit infirmata, accipiat communionem.

23 M. Ibarra, Mulier fortis..., 205; P. Allard, Les esclaves chrétiens depuis les premiers temps de l'Église jusqu' a la fin de la domination romane en Occident. Hildesheim 1974, 106-107; Sobre los malos tratos de las dueñas, cf. Juvenal, Sat., VI, 
cúa perfectamente a la mentalidad del Derecho Romano ${ }^{24}$. Parece improbable que la cotidianeidad de las agresiones de las dueñas a sus esclavas motivara la inclusión de esta falta entre las posibles que trata el Concilio de Elvira, y es posible que su inclusión obedezca a la impresión causada puntualmente por un suceso concreto, como se ha sugerido ${ }^{25}$. Sin embargo, los malos tratos de los domini varones a sus esclavos o siervos no aparecen regulados en ninguna parte del texto de Elvira. Quizá subyace en el canon la idea de que la especial debilidad, imbecillitas, o impulsividad del carácter femenino ${ }^{26}$ hace a algunas dueñas proclives a estos accesos incontrolados de cólera.

Sin embargo, llama la atención el que los redactores se refieran concretamente al caso de una sierva femenina, no generalizando la posibilidad de los malos tratos a los siervos varones. Por otro lado, el que la mujer fuera propietaria de esclavos varones es una realidad frecuentemente atestiguada en las fuentes epigráficas de época imperial en Hispania romana ${ }^{27}$, que no tuvo por qué limitarse en época bajoimperial ${ }^{28}$. Sin embargo, y aunque tal precisión pueda deberse a la impresión producida por un suceso concreto, lo cierto es que los valores morales y familiares que afloran en el texto conciliar debían de hacer cada vez menos adecuado que una mujer, especialmente cristiana, tuviera esclavos varones. Tal circunstancia supondría, cuanto menos, la proximidad de ésta a un varón que no fuera su marido. En todo caso, se tiene la impresión de las relaciones entre la mujer libre y sus siervos/as despiertan ahora un interés que no encuentra eco en el caso de los varones propietarios de esclavos.

480-483; Ovidio, Ars amat., III, 239; Plutarco, cons. ad uxor. 609c; P. de Palol, Clunia II. La epigrafía de Clunia, EAE, 1987, 49-50, donde la causa de la muerte de la domina Atia Turellia es el asesinato por parte de un siervo.

24 M. Ibarra, Mulier Fortis..., 205.

25 M. Ibarra, Mulier Fortis..., 206; M. Ibarra, «Las viudas en el Concilio de Elvira», Actas del II Congreso Peninsular de Historia Antigua, Coimbra 1993, 1086.

26 A. del Castillo, «Los impedimentos...", 338-339.

27 Cf. J. Mangas, Esclavos y libertos en España romana, Salamanca 1971; H. Gallego, Femina dignissima..., 53-61, 184-193.

28 Cf. el canon IX del Concilio de Toledo I, ya posterior, pero del siglo IV, en el que se alude a la posibilidad de que la mujer profesa o viuda fuera propietaria de esclavos: «Ninguna profesa o viuda en ausencia del obispo, o del presbítero, cantará en su casa las antífonas con ningún confesor o siervo suyom. 
En el canon $\mathrm{XXXV}^{29}$ se prohíbe que las mujeres velen en los cementerios, porque bajo el pretexto de la oración se encubrían delitos, prohibición sin duda de interpretación difícil. Quizá haga alusión a prácticas más tardías, siendo la redacción de este canon posterior al global del Concilio ${ }^{30}$, o simplemente haya que ver en ella la pervivencia de un tabú social romano, que veía con prevención la presencia de mujeres virtuosas, especialmente por la noche, en los cementerios, prevención que recuerda los agudos comentarios de Marcial sobre la vida sórdida de las bustuariae, prostitutas miserables que trabajan al aire libre, buscando el abrigo de los monumentos, aunque tenga que recurrirse a los funerarios, dejando entrever las duras condiciones de trabajo y deterioro físico de éstas ${ }^{31}$.

Además de éstos, el canon LXXXI ${ }^{32}$ prohíbe a las mujeres escribir a seglares varones en nombre propio, instando a que lo hagan siempre en el de sus maridos, y tampoco tienen que recibir cartas de amistad de alguno dirigidas a ellas solas. En este canon va implícita una importante limitación de los movimientos y de la capacidad de la mujer para actuar en nombre propio ${ }^{33}$, revelándose su contenido incompatible con la forma de vida de las importantes damas hispanorromanas que proyectaban su influencia en la vida pública municipal a través de actos de evergetismo ${ }^{34}$, colocando a sus libertos en puestos estratégicos y siendo ellas mismas objeto de todo tipo de honores públicos ${ }^{35}$, o

29 Placuit prohiberi ne feminae in cimiterio peruigitent, eo quod saepe sub obtentu orationis latenter scelera committant.

30 M. Ibarra, Mulier Fortis..., 225.

31 Cf. Marcial, Epigrammae, 1, 34; III, 93.

32 Ne feminae suo potius absque maritorum nominibus laicis scribere audeant quae fideles sunt, uel litteras alicuius pacificas ad suum solum nomen scriptas accipiant.

33 M. Ibarra, Mulier Fortis..., 238, ya incide en el extraño carácter de este canon, ajeno a las costumbres romanas y a su legislación, hasta el punto de dudar de su autenticidad. Algunos lo han interpretado como una prevención contra el adulterio. Cf. L. García Iglesias, Los judios en la España Antigua, Madrid 1978, 73; D. Ramos-Lisson, «En torno al papel de la mujer según el Concilio de llíberis», en W. Brandmüller - H. Immenkötter - E. Iserloh, Ecclesia militans. Studien zur Konzilien und Reformationonsgeschichte, I, Paderborn 1988, 88.

34 H. Gallego Franco, Femina Dignissima..., 65-76.

35 H. Gallego Franco, «Laudationes, impensa funeris, locus sepulturae: la mujer y los honores funerarios en Hispania». Hispania Antiqua. XVIII, 1994, 267-276. 
bien con aquellas mujeres que colaboraron activamente en el ámbito económico hispanorromano, como en el comercio de aceite bético ${ }^{36}$.

Es posible que tanto el canon XXXV como el LXXXI sean fruto de un añadido posterior a la celebración del sínodo de Elvira ${ }^{37}$, y somos conscientes del carácter excepcional de estos cánones, al igual que el $\mathrm{V}$, sin paralelos posibles, pero en todo caso reflejan claramente la evolución restrictiva que en el ámbito social sufrió la posición femenina en la Antigüedad Tardía hispana ${ }^{38}$. De hecho, la misma tendencia se observa en el Concilio de Zaragoza I y de Toledo I, ambos celebrados ya en un momento en que el Imperio Romano es oficialmente cristiano, y el proceso de fusión entre Iglesia y Estado iba avanzando lenta, pero inexorablemente. El canon I ${ }^{39}$ del Concilio de Zaragoza I prohíbe a las mujeres asistir a reuniones o lecciones de otros hombres que no sean sus maridos, y juntarse entre ellas con el fin de aprender o enseñar. Se apoya, por tanto, el poder del marido sobre la esposa, con el objetivo probablemente de reforzar la familia cristiana y reprimir el adulterio, a la vez que se incapacitaba a la mujer en sus aptitudes intelectuales para el estudio de la doctrina cristiana. De corte parecido es el canon IX ${ }^{40}$ del Concilio de Toledo I, que limita las iniciativas en el culto de las profesas y viudas, situando acciones como cantar las antífonas o leer el lucernario bajo la supervisión del obispo o presbítero, y primando el recinto de la Iglesia como lugar de culto, y no las residencias privadas.

$36 \mathrm{H}$. Gallego Franco, «La mujer hispanorromana y la actividad socioeconómica: las profesiones», Minerva, 7, 1993, $111-127$.

37 M. Ibarra, Mulier Fortis..., 225, 238.

38 M. Ibarra, Mulier Fortis... 247, percibe en las sancciones canónicas una paridad entre los esposos, pero lo cierto es que la imagen social de la mujer que emanan los cánones $V, X X X V$ y $L X X X I$ es ciertamente inusual en la práctica romana pagana.

39 Ut mulieres omnes ecclesiae catholicae et fideles a uirorum alienorum lectione et coetibus separentur, uel ad ipsas legentes aliae studio uel docenti uel discendi conueniant, quoniam hoc Apostolus iubet. Ab uniuersis episcopis dictum est: Anathema futuros qui hanc concili sententiam non obseruauerint.

40 Nulla professa uel uidua absente episcopo uel presbytero in domo sua antifonas cum confessore nel servo suo faciat. Lacernarium uero nisi in ecclesia non legatur: aut si legitur in villa, praesente episcopo nel presbytero uel diacono legatur. 
En conclusión, la situación de la mujer hispanorromana en la Antigüedad Tardía había cambiado. Es posible que siguiera optando a la riqueza económica y a la influencia política si pertenecía a la aristocracia imperial y senatorial y a la élite socioeconómica, pero en sus comportamientos sociales y públicos comienza a ser cada vez más limitada, poniendo a sus iniciativas una serie de trabas, sin duda con el objeto de reforzar la institución de la familia cristiana, que no se ponían al varón.

\author{
Henar Gallego Franco \\ Historia Antigua \\ Universidad de Valladolid
}

\title{
SUMARIO
}

Los cánones V, XXXV y LXXXI del Concilio de Elvira constituyen un interesante documento para el estudio de la consideración social de la mujer en la Antiguiedad Tardía hispanorromana. Estos tres cánones, de adscripción cronológica conflictiva y sin precedentes en cuanto a su contenido, sin embargo, evidencian una evolución restrictiva de la capacidad femenina de iniciativa y de movimiento al margen del mundo familiar, revelándose su esencia incompatible con la forma de vida de las importantes damas hispanorromanas del Alto Imperio.

\section{SUMMARY}

The canons 5, 35 y 81 in the Elvira Council are an interesting document to study the social position of women in Late Antiquity in Spain. Although there are some dark points in the cronological profile of these three rules, they clearly show a restrictive evolution in the movement ability of women out of the family world, and their point of view evidences a conflict of interests with the way of life of those women of upper social groups in pagan Roman Spain. 